\title{
Managing climate change risk: the case of the Italian Churches
}

\author{
Donatella Porrini ${ }^{1}$ (D) Francesco De Masi ${ }^{1}$
}

Received: 8 August 2020 / Accepted: 29 October 2020 / Published online: 18 November 2020 (c) The Author(s) 2020

\begin{abstract}
In a world of increasing and worse and worse climate events, there is an urgent need to find how to manage the climate change risk and make cultural heritage more resilient. Given the relevant threat represented by climate-related events, this paper aims to analyze the role of insurance in safeguarding cultural heritage from natural disasters. The focus is on Italian Churches seen as a particular case of study. Taking into consideration the characteristics of the managing risk strategy, we use a value-belief-norm approach and a decision tree analysis to evaluate the efficiency of the governance scheme adopted. In the case examined of the Italian Churches, the strategy is mainly based on a private insurance contract characterized by a double track, local and national, to reach the important goal of the full coverage of all churches. We conclude that cultural heritage can drive climate action and the originality of the Italian Churches strategy can represent a benchmark in this field.
\end{abstract}

Keywords Natural hazards management - Climate change risk $\cdot$ Churches $\cdot$ Cultural heritage

JEL codes $\mathrm{C} 83 \cdot \mathrm{G} 22 \cdot \mathrm{Q} 54 \cdot \mathrm{Z} 12$

\section{Introduction}

In recent decades, climate-related risks have increased as a result of changes in climate, as well as rapid and unplanned urbanization, population growth and environmental degradation (Poljanšek et al. 2017). These risks have had several impacts on human systems, such as infrastructures and buildings, as well as historical sites and monuments (Gasper et al. 2011; Ruth and Coelho 2007). There is no doubt that climate change, sustainable development and financing for development are closely connected to each other (Schmidt-Traub and Sachs 2015). Therefore, "efforts to reduce disaster risk and at the same time adapt to changing climate have become a global priority" (OECD 2020).

In the near future, the economic impacts of climate-related events are expected to increase due to the combined effect of the above-mentioned climate change and

Donatella Porrini

donatella.porrini@unisalento.it

1 Dipartimento Di Scienze Dell'Economia, Università del Salento, Lecce, Italy 
socioeconomic development, first of all in those areas that are prone to disasters (Bowen and Ebi 2015). These trends in disaster risks highlight the need to find risk managing solutions for the governance of future natural disasters (Birkland 2019).

The World Cultural Heritage is particularly exposed to this threat. "The impacts of climate change are affecting many and are likely to affect many more cultural goods in the years to come" (UNESCO 2006). Extreme weather events, floods and other catastrophes affect the conditions of several cultural goods in different countries. Hence, enhancing resilience to natural disasters and improving climate change adaptation mechanisms are two essential strategies that have to be developed to minimize damages and to define proactive management.

Climate change and its impacts can be only forecast and always with a degree of uncertainty. This threat depends on the frequency of events, magnitude, duration and impacted area (Kuzucuoglu 2013). In addition, policymakers should consider that both heritage and climate change are dynamic fields of investigation (Kalman 2014). Therefore, only through suitable monitoring and vulnerability assessment processes, can management plans be developed to ensure protection and safeguard of cultural sites. In this sense, the vulnerability of cultural heritage can sensitize people and governments and push to mitigate the effects of climate change by implementing adequate policies and tools. Cultural heritage can guide climate action by encouraging national and international organizations to establish good practices.

To reach this goal, according to the Sendai Framework for Disaster Risk Reduction, one of the key priorities is to improve societal resilience (Mechler 2016). The concept of resilience must not be limited to the capability of coping with disasters, the so-called instantaneous resilience, but instead needs to be extended to the ability to reconstruct and recover quickly or, in other words, become "dynamic resilience" (Hallegatte 2014). Considering this last definition, the Sendai Framework encourages the use of financial instruments that can reduce the potential harm of weather-related events (Mysiak et al. 2016).

The importance of the climate change threat justifies the need to develop and implement financial risk-sharing mechanisms. In particular, the European Union encourages the use of insurance against weather-related disasters since not only does it support risk sharing and coverage but also increases risk perception, promoting further action, including preventive capacity (Le Den et al. 2017).

Insurance can enhance resilience, providing financial coverage and speed of recovery (Surminski et al. 2016). It is gaining importance in preplanning, mitigation and adaptation strategies, since it can incentivize reinforcement interventions and thus minimize the exposure to risk (De Masi and Porrini 2018).

As mentioned above, evaluation, monitoring and safeguarding cultural heritage are relevant tasks for the implementation of an appropriate strategy to cope with climate-related events, in the direction to reduce the impact of natural disasters. A strategy for dealing with these events resulting from climate change should be adopted and successfully performed to protect the outstanding values of cultural heritage. In this perspective, insurance can be a useful tool to adopt for better managing such risks.

To this extent, the starting point of this paper is a literature review based on the use of the insurance tool to protect cultural heritage, identifying all the main elements to understand the benefits that can derive from a larger diffusion. Section 3 presents the case of the Italian Churches, with the aim of providing all the characteristics of the adopted strategy. In Sect. 4, the focus will be on the analysis of the value-belief-norm approach and a decision tree analysis to identify the efficiency of the insurance scheme adopted. Finally, some 
conclusive remarks outline the Italian Churches choice as a risk managing system for cultural heritage that may be extended in other scenarios.

\section{Cultural heritage and disaster insurance}

Natural disasters represent a major threat to cultural heritage, causing irreversible damage or completely destroying entire areas of cultural interest (Drdácký et al. 2007). The effects of natural disasters are clearly identifiable, and they are amplified on ancient and fragile assets where advanced techniques cannot be applied to preserve their originality (Padeletti 2019). There is extensive documentation supporting this recognition and the need to develop preventive and resilience measures aimed at the reduction in loss and damage.

A first example is provided by the H2020 HERACLES project that aims to "design, validate and promote responsive systems/solutions for effective resilience of cultural heritage against climate change effects, considering as a mandatory premise a holistic, multidisciplinary approach through the involvement of different expertise."1

UNESCO has realized a report on the relationship between Climate Change and World Heritage in 2006 and in 2007; in the document "Strategy for Risk Reduction at World Heritage Properties," UNESCO identified "five main priorities:

1. Strengthen support within relevant global, regional, national and local institutions for reducing risks at World Heritage properties;

2. Use knowledge, innovation and education to build a culture of disaster prevention at World Heritage properties;

3. Identify, assess and monitor disaster risks at World Heritage properties;

4. Reduce underlying risk factors at World Heritage properties;

5. Strengthen disaster preparedness at World Heritage properties for effective response at all levels."

Recently, the "Policy Document on the impacts of Climate Change on World Heritage properties" has provided for an online consultation, which closed on January 31, 2020, regarding the synergies between experts, international organizations and civil society to identify research opportunities for implementing risk management strategies. ${ }^{2}$

A comprehensive overview of the existing knowledge on safeguarding cultural heritage from the effects of natural disasters is included in a study published by the European Commission with the aim of supporting the implementation of risk management and preparedness strategies (Bonazza et al. 2018). In particular, the legislation put emphasis on building a culture of disaster prevention, with a specific focus on risk assessment to protect cultural heritage (Drdácký and Pospíšil 2018).

What is more, the European Commission established the Climate for Culture (CfC) project to investigate the impact of changing climate on the European Cultural Heritage simulating the effect on the internal conditions of historical buildings. ${ }^{3}$ The World Bank is promoting the employment of measures and conventions to safeguard against disaster

\footnotetext{
1 https://www.heracles-project.eu/.

${ }^{2}$ https://whc.unesco.org/en/climatechange/.

3 https://www.climateforculture.eu/.
} 
Table 1 Parish Churches in Italy Source: CEI-2020 4

\begin{tabular}{|c|c|c|c|c|}
\hline $\begin{array}{l}\text { Italian geo- } \\
\text { graphic area }\end{array}$ & Italian ecclesiastic region & $\begin{array}{l}\text { Number of Parish } \\
\text { Churches }\end{array}$ & $\begin{array}{l}\text { Local percent- } \\
\text { ages }(\%)\end{array}$ & $\begin{array}{l}\text { Geographic area } \\
\text { percentages }(\%)\end{array}$ \\
\hline \multirow[t]{5}{*}{ North } & Triveneto & 3527 & 13.78 & 49.67 \\
\hline & Lombardia & 3060 & 11.95 & \\
\hline & Piemonte & 2206 & 8.62 & \\
\hline & Liguria & 1250 & 4.88 & \\
\hline & Emilia-Romagna & 2672 & 10.44 & \\
\hline \multirow[t]{5}{*}{ Center } & Toscana & 2431 & 9.50 & 24.88 \\
\hline & Marche & 823 & 3.22 & \\
\hline & Umbria & 599 & 2.34 & \\
\hline & Lazio & 1471 & 5.75 & \\
\hline & Abruzzo-Molise & 1045 & 4.08 & \\
\hline \multirow[t]{4}{*}{ South } & Campania & 1833 & 7.16 & 16.26 \\
\hline & Puglia & 1060 & 4.14 & \\
\hline & Basilicata & 274 & 1.07 & \\
\hline & Calabria & 996 & 3.89 & \\
\hline \multirow[t]{2}{*}{ Islands } & Sicilia & 1732 & 6.77 & 9.18 \\
\hline & Sardegna & 619 & 2.42 & \\
\hline Total & & 25,598 & 100.00 & 100.00 \\
\hline
\end{tabular}

risks and to strengthen resilience, making disaster resilience an intrinsic part of cultural heritage management (World Bank Group 2017).

Although there are several projects in this field, a lack of dissemination of the outcomes of scientific research to managers of cultural heritage in the context of adaptation to climate change impacts (Sesana et al. 2019) has emerged. The literature outlines that, due to the high exposure to climate-related events, it is necessary to define guidelines and recommendations to implement these kinds of measures to obtain not only cultural heritage protection but also enhance the preparedness of landscape for natural disasters (Dastgerdi et al. 2019). As our climate continues to change, our cultural heritage will potentially be exposed to diverse pressures and to risks not previously experienced (Sesana et al. 2020).

In any case, as stated before, the majority of papers in this field deal with the management strategy of a specific risk event. Some works present an analysis of the impact of earthquakes (Ravankhah et al. 2017; Sugio 2015; Toki 2011). Some others focus on another important threat: fire (Ferreira et al. 2016; Marrion 2016). As directly linked, bushfires take relevance in this field. Since during and after a bushfire cultural heritage is highly exposed, an in-depth study about the Australian Bush Fire Management Plans and its suitability is provided by Laidlaw et al. (2008).

An interesting perspective is represented by Figueiredo et al. (2019). They propose a framework to provide a preliminary assessment of risk for a large number of cultural assets exposed to flood risk in Portugal, with the computation of specific indices for each exposed asset.

$\overline{{ }^{4} \text { https://www.chiesacattolica.it/annuario-cei/regioni-diocesi-e-parrocchie/. }}$ 
As shown by several kinds of research, flood-related disasters represent one of the most frequent, serious and damaging events that affect cultural heritage, with many studies in the literature about the mapping, prevention and safeguard of the same (Deschaux 2017; Reimann et al. 2018; Wang 2015).

In the analysis of literature, it emerged that the relationship between cultural heritage and natural disasters is relevant in many different perspectives. Although a lack of study about climate change and cultural heritage can be found, there is an increasing interest in the topic together with the need to adopt an interdisciplinary approach in assessing cultural heritage and resources (Fatorić and Seekamp 2017).

This is why, in order to achieve an effective strategy, insurance emerges as a relevant tool to be adopted. Insurance, in fact, is a complementary countermeasure for unexpected losses brought about by natural hazards (Gizzi et al. 2020). In particular, it is characterized by three economic roles: risk transfer, risk pooling and risk allocation. By a careful examination of its characteristics, insurance can aid in better understanding all the risks connected to extreme events and in decreasing the relative immediate long-term financial losses (Kunreuther 2015). Furthermore, insurance is an instrument that should to be used to safeguard cultural heritage from disasters and not to commodify cultural goods (Vecco and Imperiale 2017).

Even though it is expensive to repair after a natural disaster has occurred, insurance can cover an important role in this field. It can provide damages compensation to finance in whole or in part repair or reinstatement, depending on the event and its consequences. What is more, it can also improve the knowledge of vulnerability and the exposure to disaster, necessary for the calculation of the premium. Hence, it allows an effective preservation of cultural assets and a financial coverage to withstand extreme events.

Due to climate change, the latter and, in particular, floods are expected to rise. Therefore, there is a growing recognition that insurance could incentivize people "to act in a risk reducing way, triggering adaptation activities and addressing the underlying physical risks that influence the impact of flooding" (Surminski and Eldridge 2017).

The protection of key cultural heritage items should be regarded as a fundamental strategy to adopt, due to the centrality of the cultural heritage in the emotional well-being of an affected community in the disaster recovery phase (Spennemann and Graham 2007). It is in this light that in the following sections the case study proposed is the recourse to the insurance instrument in the context of Italian Churches.

\section{The Italian Churches: features and governance structure}

According to Throsby's classification (2001), a cultural good is characterized by the following values: aesthetic, historical, social, spiritual and symbolic. Churches, and in particular Italian Churches as the object of this paper, represent with any doubt an important component of the cultural heritage of a country, because they satisfy all the values required by the above classification. They are tangible evidence of our history and culture, and for this reason, they need to be protected from the increasing threat of natural disasters, to safeguard them for future generations. 
In Italy, there are 25,598 Parish Churches. According to Article 515 of the Code of Canon Law, a Parish is defined as "a certain community of the Christian faithful stably constituted in a particular church, whose pastoral care is entrusted to a pastor ("parochus") as its proper pastor ("pastor")." As a general rule, a Parish "is to be territorial, that is, one which includes all the Christian faithful of certain territory," as stated by the Article 518 of the Code of Canon Law.

Examining the Italian geographic areas, we can see that churches are well distributed in the national territory, as shown in Table 1.

In the first column of Table 1, the Italian territory is split into four areas (North, Center, South and Islands), with a more detailed distinction indicated in the second column where these four areas are further divided into the Italian Ecclesiastic Regions of competence. According to this territory partition, in the next three columns data, respectively, describe the number of Parish Churches in each Ecclesiastic Region, the percentage of diffusion in each Ecclesiastic Region and the total percentage related to the four main geographic areas.

As shown in Table 1, the half of Parish Churches are situated in the North of Italy given the breadth of the territory ${ }^{5}$ and the population density ${ }^{6}$ with respect to the Center, the South and the Islands of the country.

The Parish Churches are structured into Dioceses that are headed by Bishops. ${ }^{7}$ In particular, a Diocese is defined as "a portion of the people of God which is entrusted to a Bishop for him to shepherd with the cooperation of the presbyterium," according to Article 369 of the Code of Canon Law. In other words, it is a religious territorial portion held by a Bishop who has "all ordinary, proper, and immediate power which is required for the exercise of his pastoral function" (art. 381, Code of Canon Law).

The Italian Churches stand out due to their religious significance, and therefore they are particularly important for the community, so that it allows us to consider them as a particular case of study. In fact, churches are not only cultural goods, as said before, but they also contain relevant cultural goods, such as paintings and monuments, that meet the need for representation and proof of Jesus's and Saints' lives, in a doctrinal vision. By admiring the architectural and artistic beauties both inside and outside, the message they communicate is a sense of holiness and solemnity. Very often churches are built not only to be admired from the outside but above all to embrace the community of believers.

Unfortunately, these precious cultural goods are exposed to climate-related disasters risks. To have an idea of the exposure level of the cultural heritage in Italy, ISPRA (Istituto Superiore per la Protezione e la Ricerca Ambientale-The Italian Institute for Environmental Protection and Research) realizes reports regarding the hydrogeological risks

${ }^{5}$ Italian territory breadth: (Source: ISTAT).

- North 120,255.82 $\mathrm{km}^{2}$;

- Center 68,916.88 km²;

- South $62,967.72 \mathrm{~km}^{2}$;

- Islands $49,932.41 \mathrm{~km}^{2}$.

${ }^{6}$ Italian population density: (Source: ISTAT).

- North 1,167 inhabitants/ $/ \mathrm{km}^{2}$;

- Center 890 inhabitants $/ \mathrm{km}^{2}$;

- South 883 inhabitants $/ \mathrm{km}^{2}$;

- Islands 262 inhabitants $/ \mathrm{km}^{2}$.

${ }^{7}$ In Italy, there are 227 Dioceses. 


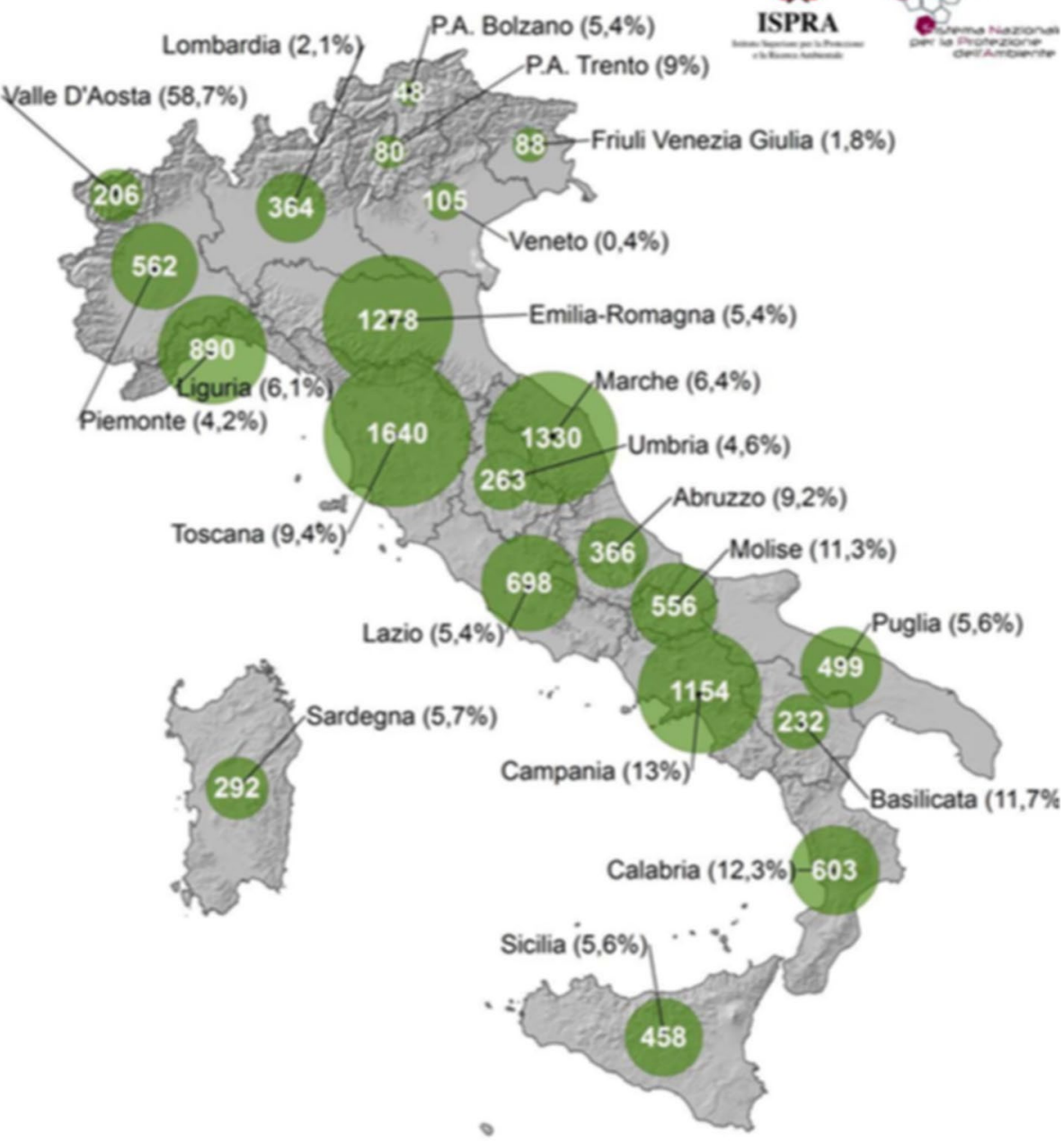

Fig. 1 Map of cultural assets at risk of landslides along the national territory. The number in the circles represents the number of cultural assets at risk of landslides in each region. Source: ISPRA (2018, p 103)

in Italy. Particularly, ISPRA (2018) provides recent data about the cultural assets at risk of landslides in Italy $(37,847$ equal to $18.6 \%$ of the total) and about the cultural assets at risk of floods $(39,426$ equal to $19.4 \%$ of the total).

The two figures show the exposure of the Italian cultural assets ${ }^{8}$ to two specific natural disasters: Fig. 1 focuses on landslides, while Fig. 2 focuses on floods. These risks are directly related to climate change, since they can be considered as a consequence of increasing temperatures. While for landslides the risk is well distributed in the country with a prevalence in the Center of Italy, for floods the risk is concentrated above all in the

\footnotetext{
${ }^{8}$ ISPRA considers cultural assets such as the set of historical centers, medieval villages, monuments, historical and religious buildings, churches and archeological sites.
} 


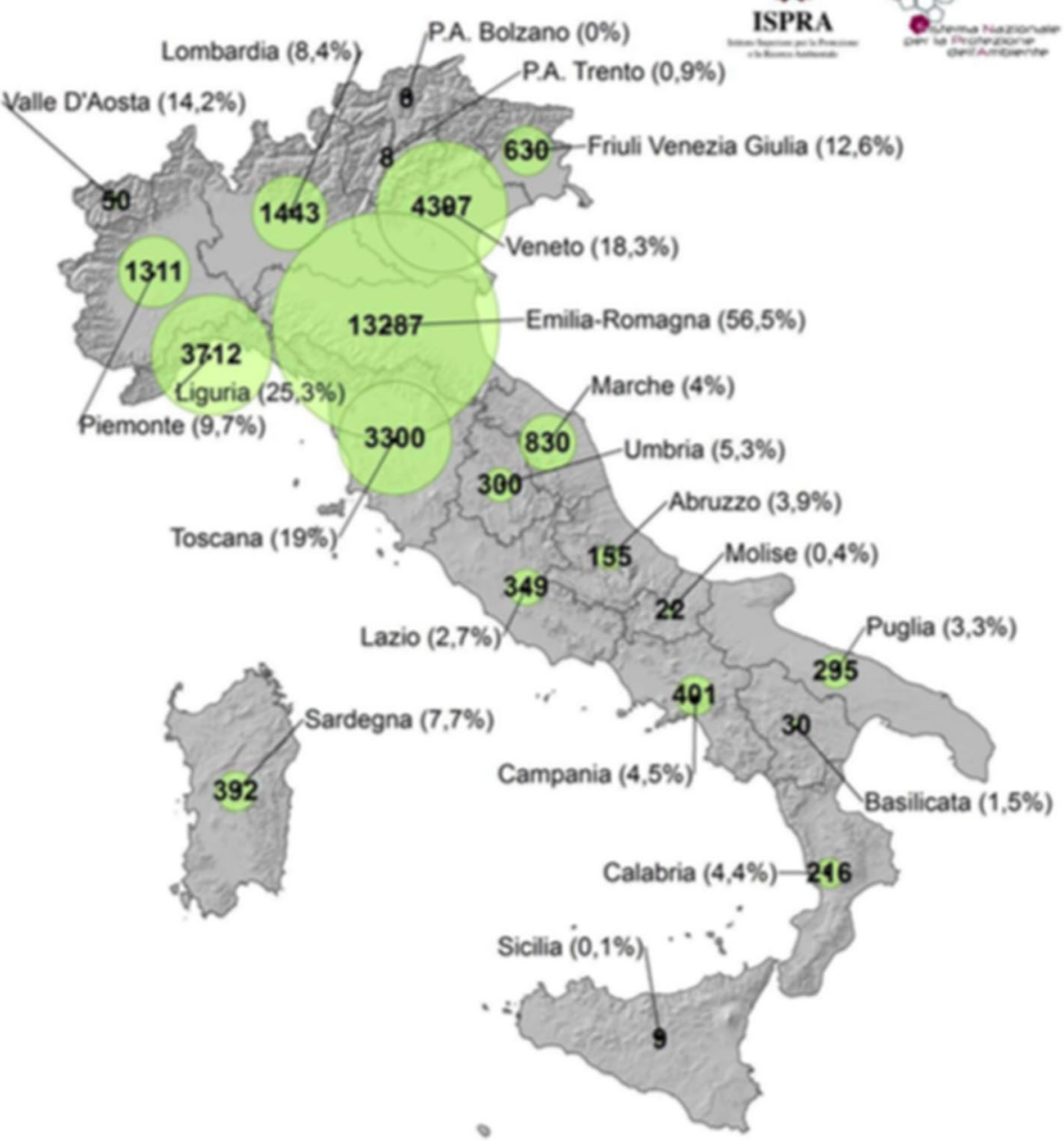

Fig. 2 Map of cultural assets at risk of flood along the national territory. The number in the circles represents the number of cultural assets at risk of flood in each region. Source: ISPRA (2018, p. 145)

North. Considering the two maps together, it emerges that the Italian territory is highly exposed to these climate-related events and each region presents specific risks connected with the natural exposure of each area. Comparing Table 1 regarding church distribution and Figs. 1 and 2, on the cultural assets at risk, the need to develop a climate change risk management strategy at a national level comes to light in relation to cultural assets, and churches in particular.

Looking at the specific case, the institution that assumes the responsibility of the governance of all religious administrations, including risk management, is the CEI (Conferenza Episcopale Italiana-Italian Episcopal Conference) the "college of Bishops, whose head is the Supreme Pontiff and whose members are Bishops. It is also subject of supreme 
and full power offer the universal Church," according to the Article 336 of the Code of Canon Law.

In July 2018, CEI entered into an agreement with an Italian insurance company to establish a national insurance plan to safeguard the cultural heritage represented by churches. This agreement is called "Sant'Emidio Project" in honor of the patron saint of Ascoli Piceno, protector of the earthquakes that often hit this city in the Center of Italy. As far as we know, it is the first agreement at national level for the insurance coverage of a specific cultural heritage (the 25,598 Italian Parish Churches).

Taking into consideration a more technical and legal perspective, this agreement can be classified as a private contract, since the two contractors are two private entities. There are no state subsidies that characterize a multi-sector partnership, the so-called PPP (public-private partnership) (Kunreuther and Lyster 2016). All the contractual aspects are based on a private agreement without any imposition or intervention from the state.

The uniqueness of this system also comes from the existence of a double track: One track is specifically structured for the coverage of natural disasters and is directly signed by CEI, while the other is complementary, in the sense that is related to all the other events that can affect the churches and is signed by each Diocese.

The two tracks differ for several aspects, although they are complementary to each other. The main difference is in the insurance coverage provided: While the first track refers to a national coverage, the second is related to a local one. This means that the responsibility for the national contract is of the Italian Episcopal Conference that assumes the role of managing high risks, specifically those related to natural disasters. Instead, at a local level, each Diocese may intervene to define a form of complementary contract to insure churches against other risks. In this way, an all-encompassing insurance coverage for different kinds of risks can be obtained.

As can be seen from the above, this agreement is structured so that there is a unique disaster risk management strategy at national level, but with local diversification. This choice may arise from the particular governance of the churches in Italy that reflects the historical, artistic and religious values of this particular cultural good. This aspect will be explored in the next section.

\section{An analysis of the Italian Churches insurance system}

\subsection{Value-belief-norm approach}

To investigate the motivations behind the risk management choice of the Italian Churches, the value-belief-norm (VBN) theory can be well applied. This theory defines how an environmental movement or behavior can be explained by a social psychological approach based on a conjunction of values, beliefs and personal norms that impel individuals to act in ways that support a movement's goals (Stern et al. 1999). Starting from the identification of some basic human values, "each movement's ideology contains specific beliefs about consequences and responsibilities which, in conjunction with chosen values, activate personal norms that oblige individuals to support the movement's goals" (Stern et al. 1999). To this extent, the three main elements of the VBN theory are identified as follows:

1. Value refers to "a guiding principle for any behavior based on desirable trans-situation goals, which vary in relative importance" (Schwartz 1992); 


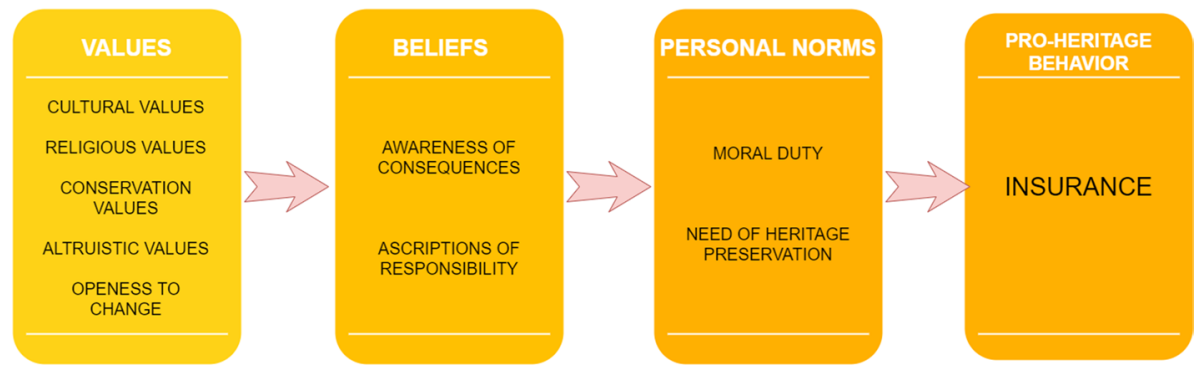

Fig. 3 Value-belief-norm chain

2. Belief is related to one's thoughts and has two main components: awareness of consequences and ascriptions of responsibility (Stern 2000);

3. Personal norms mean feelings of moral duty to preserve the environment (Tanner and Kast 2003).

Although the majority of papers based on the VBN theory deal with environmental issues (Fornara et al. 2016; Ghazali et al. 2019; Han 2015; Lind et al. 2015; Oreg and KatzGerro 2006), this article proposes its adoption to describe the insurance choice as a risk management system to safeguard cultural heritage.

\subsection{The research analysis}

Looking at the Italian Churches case of study, it seems that this theory can be applied, since the risk management choice made by the CEI starts from the awareness of certain important values.

As said in Sect. 3, churches represent important components of the Italian Cultural Heritage because they are characterized by great artistic, historical and religious values. These aspects assume great importance since religious administrators have the role of managing and safeguarding this heritage for the future generations. Therefore, the awareness and the sensitivity of the ecclesiastic world toward its protection may be a fundamental reason behind their risk management choice.

The awareness of consequences related to extreme events on churches, together with the ascription of responsibility, exactly represents the CEI beliefs. The CEI, as the Italian Episcopal Conference, finds itself responsible for the governance of such heritage. Consequently, it assumes the role of the management of high risks, especially those connected to natural disasters and climate-related events and the combined effect of their beliefs influences how they should intervene.

The awareness of the adverse consequences of a catastrophic event and the great motivation to safeguard churches, deriving from the knowledge of the cultural and religious relevance of churches and their risk exposure, drives the strategic decision to take out an insurance policy at national level as an effective means against natural disasters. This risk management strategy demonstrates the openness to change of the Italian ecclesiastic administrators, who made an unprecedented and innovative choice that has allowed for the financial coverage of all churches. 


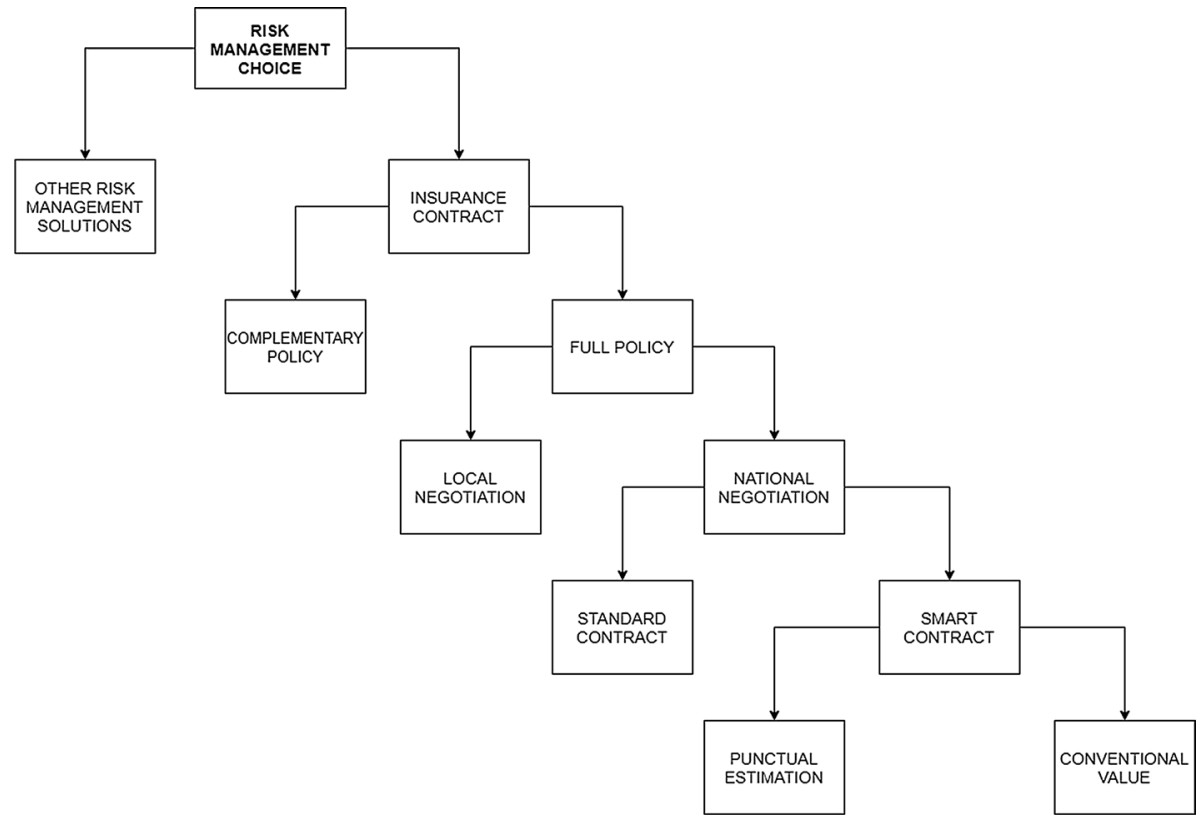

Fig. 4 Risk management choice decisions tree

In this way, the causal chain of the value-belief-norms is created: values (mainly cultural, religious, altruistic, conservation and openness to change values), beliefs (awareness of consequences and ascriptions of responsibility) and norms for protection.

Graphically, it can be represented as follows.

As shown in Fig. 3, the causal chain starts from the identification of well-defined values that mark the way to administer churches. All these values are highly considered since the awareness of such heritage and the related risk exposure activates a sense of moral duty that creates a predisposition to act in safeguarding churches. Each of these variables in the chain influences the next, up to the identification of the action that is then carried out.

All three dimensions are highly connected to each other and allow the possibility to find the solution that best suits the case. Focusing on the third and last element of the chain, the insurance choice made by the CEI, a unique system covering all nearly the 26,000 Italian Churches against climate change effects, appears as a particular risk management choice.

As concerns the value-belief-norm chain, the CEI feels the duty to protect the cultural heritage represented by churches and identifies in insurance a useful tool to reach the goal. To evaluate whether these values, beliefs and norms are reflected in the insurance agreement, a decision tree analysis scheme is applied in the next section.

\subsection{The decision tree analysis}

As stated in the previous section, the governance of the churches as historical monuments is in the hands of the ecclesiastic administrators that made an unprecedented choice to cover all churches with an insurance national policy. 
In this section, the risk management decisions are deeply analyzed to identify all the steps to the constitution of the final system of insurance coverage for natural disaster coverage for the Italian Churches.

The scheme proposed in Fig. 4 shows the decisions tree of the risk management choice. As a preliminary step, the first decision is between insurance and other risk management instruments. Once the choice is for insurance, the decision is between "full" rather than a "complementary" insurance coverage.

Before the so-called Sant'Emidio Project in July 2018, each Diocese was able to sign a complementary insurance contract providing for coverage of damages as a consequence of natural disasters. In a survey taken in the first months of the 2018, De Masi and Porrini (2020) show that $62 \%$ of the Italian Dioceses interviewed declared to have signed an insurance policy to cover the damages deriving from natural disasters. In contrast, according to ANIA (2018), there was a much lower level of penetration in the Italian insurance market for private houses (around 2.5\%). The Dioceses' high level of penetration of complementary policies before 2018 already proves the effects of values, beliefs and norms also at local level. But, in case of high risks connected with extreme events like climate-related ones, it is necessary to provide an insurance contract that can cover all the "population at risk" (all the Italian Churches in the case study here considered). In this sense, the "full policy" provided by the CEI appears as a very efficient solution in terms of diffusion of these kinds of policies and management of the related risks.

The next stage of decision is the one related to a "national" versus a "local" negotiation. The agreement signed by the CEI corresponds to a one-party contract with an Italian insurance company. As a national scheme that provides the same insurance contracts for all the Italian Churches, it is particularly efficient in avoiding the issue of "adverse selection," considered one of the most common problems in the insurance market for natural disaster coverage (Porrini and Schwartze 2014). Since the national contract covers all the Italian Churches, this means that not only the ones with high risks can purchase the policies. This leads to a better market functioning and an overall lower level of premium.

Besides, if risk concentration is realized at a national level, at a local level market competition emerges given that each Diocese can take out a complementary contract with any insurance company and not necessarily with the same that insures against disaster risks at a national level.

Looking at the first and the second stages of the decision, different risks emerge, leading to different amounts of premiums. In fact, from an economic point of view, a higher level of risk is reflected in a higher level of insurance premium, given that the level of risk means the "probability of harmful consequences, or expected losses resulting from interactions between natural or human-induced hazards and vulnerable conditions" (UNISDR 2009). Therefore, the higher the risk, the more probable the event and the higher the premium is. In the case considered, the coverage of natural disasters requires a very high level of premiums; therefore, the management is entrusted to the CEI, as a national institution with greater economic availability than the local Dioceses. The latter could set up a complementary insurance contract for other events corresponding to smaller risks and lower premiums.

The fourth stage presents another aspect that contributes to making this risk management strategy innovative. The national contract can be defined as a "smart contract" in the sense that it is constantly evolving in relation to some technical contractual aspects that can change over time. According to what expressed by the CEI, some changes can be applied, especially considering those related to risk exposure and relative premium. As an example, 
Table 2 Characteristics of the insurance contract

\begin{tabular}{ll}
\hline Elements & Description \\
\hline Nature & Private contract-No state intervention or imposition \\
Contractor & CEI-Italian Episcopal Conference \\
Negotiation & National \\
Typology & $\begin{array}{l}\text { Smart contract-It is constantly evolving in relation to some technical contractual aspects } \\
\text { that can change over time. According to needs expressed by the CEI, some changes can } \\
\text { be applied, considering especially those related to risk exposure and relative premium }\end{array}$ \\
& $\begin{array}{l}\text { Double track: } \\
\text { Directly signed by the CEI, it aims to cover churches from natural disasters }\end{array}$ \\
& $\begin{array}{l}\text { Signed by each Diocese, it aims to cover churches from all the other events, in a comple- } \\
\text { mentary perspective }\end{array}$ \\
& $\begin{array}{l}\text { National coverage-All Italian Parish Churches are insured against natural disasters } \\
\text { Coverage }\end{array}$ \\
Estimation & Conventional values based on a national mean of church values, with the identification of \\
& classes of values and the relative premiums associated with each class \\
\hline
\end{tabular}

if some reinforcement work is done, the contract can change and therefore require a lower premium.

Since disaster risk is constantly changing, it may be seen as a developmental issue. Insurance seems to be suitable to cover this role, with flexible contracts that allow for an efficient risk reduction strategy. "Insurance premiums based on risk provide signals to residents and business as to the hazards they face and enable insurers to lower premiums for properties where steps have been taken to reduce their risk" (Kunreuther and Lyster 2016).

The fifth decisional stage corresponds to the identification of the value to be insured. The definition of the value can represent a big problem in relation to objects of high value, as the churches in our case. Assessing an economic value to cultural heritage may require a complex estimate, with a particular focus on the measurement of "the value of the flow of services yielded by the cultural good and to estimate its value as an item of cultural capital stock" (Throsby and Zednik 2014). A specific estimation may require much time, and this could make insurance contracts difficult to be formulated. Nevertheless, this technical problem has been solved in the case of the Italian Churches. In detail, they have adopted conventional values based on a national mean of church values, with the identification of classes of values and the relative premiums associated with each class.

The adopted criteria for defining the Parish Churches conventional value are based on the following five elements: historical accuracy, quality and quantity of cultural goods set in a church, recent restorations and architectural relevance. Through actuarial technique methodology, a specific class of value is associated with a corresponding relative premium for each class, according to the correspondence of each church to these five criteria. The direct effect of this method is therefore the identification of a way to attribute an economic value to such a great cultural heritage.

To sum up all the characteristics above described, in Table 2 they are laid out in a more schematic way in order to highlight the main features of the insurance contract.

Following Table 2, effects and advantages are now summarized as a means to define this particular insurance contract as an efficient solution in the coverage of damages deriving from natural hazards. The uniqueness of this system indeed derives from all the characteristics and the relative effects described in Table 3. 


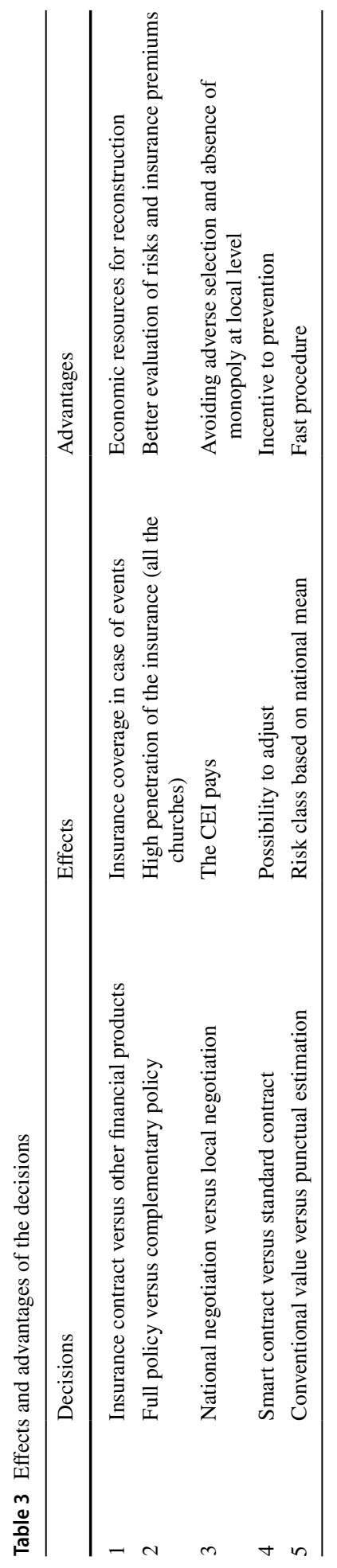


Table 4 Number of European Cathedrals Source: GCatholic. org $2020^{9}$

\begin{tabular}{lrlr}
\hline Country & Cathedrals & Country & Cathedrals \\
\hline Albania & 5 & Liechtenstein & 1 \\
Austria & 12 & Lithuania & 8 \\
Belgium & 9 & Luxembourg & 1 \\
Belarus & 4 & Macedonia & 2 \\
Bosnia-Herzegovina & 4 & Malta & 2 \\
Bulgaria & 3 & Moldova & 1 \\
Cyprus & 1 & Monaco & 1 \\
Croatia & 16 & Montenegro & 2 \\
Czech Republic & 9 & Netherlands & 7 \\
Denmark & 1 & Norway & 3 \\
Estonia & 1 & Poland & 44 \\
Finland & 1 & Portugal & 21 \\
France & 93 & Romania & 13 \\
Georgia & 1 & Russia & 5 \\
Germany & 29 & Serbia & 5 \\
Great Britain & 39 & Slovakia & 12 \\
Greece & 11 & Slovenia & 6 \\
Hungary & 16 & Spain & 74 \\
Ireland & 22 & Sweden & 1 \\
Iceland & 1 & Switzerland & 8 \\
Latvia & 4 & Ukraine & 23 \\
\hline & & & \\
\hline
\end{tabular}

As Table 3 shows, the management strategy chosen has relevant effects and advantages for the insurance market functioning. At first, it allows for the identification of the economic resources for the reconstruction, through reimbursement that can be obtained in force of the insurance contract undertaken. In addition, thanks to the full policy deriving from the national negotiation, a better evaluation of risk is reached with the identification of the relative insurance premiums. This implies another effect: the absence of adverse selection. Since the national contract covers all the Italian Churches, this means that not only those with higher risk can purchase the policy. This leads to a better market functioning and a general lower premium.

What is more, risks are diversified for the contractors and the relative coverage strategy, avoiding scenarios of market malfunctioning or failure. Since at a local level each Diocese is free to choose its own insurance company for the complementary coverage, monopoly power is avoided.

The fourth and fifth effects shown in Table 3 affect two technical aspects. The first is the incentive to prevention that derives from the smart contract: Thanks to its structure, this policy offers the possibility to modify some contractual aspects according to needs expressed by the CEI. The second is related to the fast procedure obtained thanks to the conventional values scheme.

The combined effect of all these elements leads to a well-structured agreement, with many aspects that make it unique and a possible benchmark in disaster risk management.

${ }^{9}$ https://www.gcatholic.org/churches/cath.htm. 
Besides, the so-developed strategy takes relevance not only in a national perspective but also in an international one. As a confirmation of what has been affirmed above, after the fire that hit Notre-Dame de Paris in April 2019, it was declared that it was not insured. The Parisian Cathedral indeed is owned by the State which, in the absence of an insurance obligation, had to pay for the entire reconstruction of the religious monument. This is a widespread situation given that 83 of the 93 cathedrals in France do not have insurance coverage, since the importance of insurance as a countermeasure against disasters has not yet been recognized.

This episode puts more emphasis on the Italian agreement, contributing to identifying it as a benchmark in the international context.

What is more, in order to have a perception of the number of great cultural heritages represented by churches, Table 4 shows the number of cathedrals in Europe, differentiated by country.

Looking at Table 4, a considerable number of cathedrals in European Countries can be seen, with some differences related to the religiousness of each state. They represent an important component of the cultural heritage of a country, and therefore they should be preserved in a special way.

Comparing these data with the Italian ones, an interesting consideration can be made. Although the number of Italian Cathedrals is greater than in any other European Country, steps toward protection have been taken.

As a matter of fact, following the example of the Italian agreement, it could be possible to develop specific insurance contracts that can cover cathedrals and churches from natural hazards. It represents a potential for developing insurance markets seen as an effective countermeasures against these events.

"Cathedrals are part of our history and culture: having inherited this from the past, it is absolutely important to safeguard it for future generations" (De Masi and Porrini 2020). This is why it would be desirable to define solutions, both private and public, to insure cathedrals as well as other cultural goods, enhancing in this way the role cultural heritage has in our society.

\section{Conclusion}

In a world of increasing and worse and worse climate events, there is an urgent need to adapt to climate change as an opportunity to make cultural heritage more resilient. It has been suggested that multi-sector partnerships can be effective to encourage adaptation to climate change risks, which consist in collaboration between different private or public agents and institutions (Bowen and Ebi 2015). Nevertheless, from the analyzed case, it appears that private solutions can be well adopted as a risk management strategy, with efficient solutions like the one applied in Italy.

"If adequately motivated, people have a key role not only in observing climate change and the related events but also in developing adaptive models to cope" (Kim 2011). Thanks to the sensitivity and the openness to change shown by the CEI, it has been possible to define a very particular approach based on the recourse to the insurance market. Through a national policy undertaken with an insurance company, all churches are now covered from the risk of natural disasters and climate-related events. The national and 
local double track has allowed for the achievement of an important goal: the full coverage of all churches.

The Italian strategy can be therefore considered as a benchmark in this field and can be well applied in several contexts, with the aim of reaching an efficient risk management and an optimal governance.

Funding Open access funding provided by Università del Salento within the CRUI-CARE Agreement.

\section{Compliance with ethical standards}

Conflict of interest The authors declare that there is no conflict of interest, which includes all financial and non-financial interests and relationships.

Open Access This article is licensed under a Creative Commons Attribution 4.0 International License, which permits use, sharing, adaptation, distribution and reproduction in any medium or format, as long as you give appropriate credit to the original author(s) and the source, provide a link to the Creative Commons licence, and indicate if changes were made. The images or other third party material in this article are included in the article's Creative Commons licence, unless indicated otherwise in a credit line to the material. If material is not included in the article's Creative Commons licence and your intended use is not permitted by statutory regulation or exceeds the permitted use, you will need to obtain permission directly from the copyright holder. To view a copy of this licence, visit http://creativecommons.org/licenses/by/4.0/.

\section{References}

ANIA (2018) L'assicurazione Italiana, 2017-2018, Roma.

Birkland TA (2019) Natural Hazards Governance: an overview of the field. Oxford Encyclopedia of Natural Hazards Governance, Oxford University Press, Oxford. https://doi.org/10.1093/acrefore/9780199389 407.013.358

Bonazza A, Maxwell I, Drdácky M, Vintzileou E, Hanus C (2018) Safeguarding Cultural Heritage from Natural and man-made disasters-a comparative analysis of risk management in the EU. Working Paper, Publication Office of the European Union, Brussels. https://doi.org/10.2766/224310

Bowen KJ, Ebi KL (2015) Governing the health risks of climate change: towards multi-sector responses. Curr Opin Environ Sustain 12:80-85. https://doi.org/10.1016/j.cosust.2014.12.001

Dastgerdi AS, Sargolini M, Pierantoni I (2019) Climate change challenges to existing cultural heritage policy. Sustainability (Switzerland). https://doi.org/10.3390/su11195227

De Masi F, Porrini D (2018) Vulnerability to natural disasters and insurance: insights from the Italian case. Int J Financial Stud. https://doi.org/10.3390/ijfs6020056

De Masi F, Porrini D (2020) Cultural heritage and natural disasters: the insurance choice of Italian Cathedrals. J Cult Econ. https://doi.org/10.1007/s10824-020-09397-x

Deschaux J (2017) 4-Flood-related impacts on cultural heritage.In: Vinet FBT-F (ed) pp. 53-72. Elsevier, Amsterdam. https://doi.org/10.1016/B978-1-78548-268-7.50004-3

Drdácký M, Binda L, Herle I, Lanza L (2007) Protecting the cultural heritage from natural disasters. Advanced Research Centre for Cultural Heritage.

Drdácký M, Pospísil S (2018) European Initiatives and recommendations for the Safeguarding of $\mathrm{CH}-$ Flood-Landslides-Storm Risk. ProteCHt2save Conference 2018.

Fatorić S, Seekamp E (2017) Are cultural heritage and resources threatened by climate change? Climatic Change, A systematic literature review. https://doi.org/10.1007/s10584-017-1929-9

Ferreira TM, Vicente R, Mendes R, da Silva JA, Varum H, Costa A, Maio R (2016) Urban fire risk: evaluation and emergency planning. J Cult Herit. https://doi.org/10.1016/j.culher.2016.01.011

Figueiredo R, Romão X, Paupério E (2019) Flood risk assessment of cultural heritage at large spatial scales: framework and application to mainland Portugal. J Cult Herit. https://doi.org/10.1016/j.culhe r.2019.11.007

Fornara F, Pattitoni P, Mura M, Strazzera E (2016) Predicting intention to improve household energy efficiency: the role of value-belief-norm theory, normative and informational influence, and specific attitude. J Environ Psychol 45:1-10. https://doi.org/10.1016/j.jenvp.2015.11.001 
Gasper R, Blohm A, Ruth M (2011) Social and economic impacts of climate change on the urban environment. Curr Opin Environ Sustain 3(3):50-157. https://doi.org/10.1016/j.cosust.2010.12.009

Ghazali EM, Nguyen B, Mutum DS, Yap S-F (2019) Pro-environmental behaviours and value-beliefnorm theory: assessing unobserved heterogeneity of two ethnic groups. Sustainability. https://doi. org/10.3390/su11123237

Gizzi FT, Kam J, Porrini D (2020) Time windows of opportunities to fight earthquake under-insurance: evidence from Google Trends. Human Soc Sci Commun 7:61. https://doi.org/10.1057/s41599-020-0532-2

Hallegatte S (2014) Economic resilience: definition and measurement. World Bank Policy Research Working Paper.

Han H (2015) Travelers' pro-environmental behavior in a green lodging context: Converging value-beliefnorm theory and the theory of planned behavior. Tour Manage 47:164-177. https://doi.org/10.1016/j. tourman.2014.09.014

ISPRA (2018) Dissesto idrogeologico in Italia: pericolosità e indicatori di rischio - Edizione 2018. Edited by Trigila A., Iadanza C., Bussettini M., Lastoria B., Rapporti 287/2018.

Kalman H (2014) Heritage planning principles and process; Routledge: New York, NY, USA,

Kim HE (2011) Changing climate, changing culture: adding the climate change dimension to the protection of intangible cultural heritage. Int J Cult Property. https://doi.org/10.1017/S094073911100021X

Kunreuther H (2015) The role of insurance in reducing losses from extreme events: the need for public-private partnerships. Issues and Practice, Geneva Papers on Risk and Insurance. https://doi.org/10.1057/ gpp. 2015.14

Kunreuther H, Lyster R (2016) The role of public and private insurance in reducing losses from extreme weather events and disasters. Asia Pacific J Environ Law. https://doi.org/10.4337/apjel.2016.01.02

Kuzucuoglu AH (2013) Summary for policymakers. In: Intergovernmental Panel on Climate Change (ed) Climate change 2013 - the physical science basis. Cambridge University Press, Cambridge, pp 1-30. https://doi.org/10.1017/CBO9781107415324.004

Laidlaw P, Spennemann DHR, Allan C (2008) Protecting cultural assets from bushfires: a question of comprehensive planning. Disasters. https://doi.org/10.1111/j.1467-7717.2007.01027.x

Le Den X, Persson M, Benoist A, Hudson P, de Ruiter M, de Ruig L, Kuik O (2017) Insurance of weather and climate-related disaster risk: inventory and analysis of mechanisms to support damage prevention in the EU. Publications Office of the European Union

Lind HB, Nordfærn T, Jørgensen SH, Rundmo T (2015) The value-belief-norm theory, personal norms and sustainable travel mode choice in urban areas. J Environ Psychol 44:119-125. https://doi. org/10.1016/j.jenvp.2015.06.001

Marrion CE (2016) More effectively addressing fire/disaster challenges to protect our cultural heritage. J Cult Herit. https://doi.org/10.1016/j.culher.2016.03.013

Mechler R (2016) Reviewing estimates of the economic efficiency of disaster risk management: opportunities and limitations of using risk-based cost-benefit analysis. Nat Hazards 81(3):2121-2147. https ://doi.org/10.1007/s11069-016-2170-y

Mysiak J, Surminski S, Thieken A, Mechler R, Aerts J (2016) Brief communication: Sendai framework for disaster risk reduction-success or warning sign for Paris? Natural Hazards Earth Syst Sci 16(10):2189-2193. https://doi.org/10.5194/nhess-16-2189-2016

OECD (2020) Climate change adaptation and disaster risk reduction. https://doi.org/10.1787/3edc8 d09-en

Oreg S, Katz-Gerro T (2006) Predicting proenvironmental behavior cross-nationally. Environ Behavior 38(4):462-483. https://doi.org/10.1177/0013916505286012

Padeletti G (2019) Heritage resilience against climate events on site-HERACLES Project: mission and vision. Communications in Computer and Information Science, pp. 360-375. https://doi. org/10.1007/978-3-030-12957-6_26

Poljanšek K, Marin Ferrer M. De Groeve T, Clark I (eds) (2017) Science for disaster risk management 2017: knowing better and losing less. EUR 28034 EN, Publications Office of the European Union, Luxembourg, ISBN 978-92-79-60679-3, https://doi.org/10.2788/842809, JRC102482.

Porrini D, Schwarze R (2014) Insurance models and European climate change policies: an assessment. Euro J Law Econ 38(1):7-28. https://doi.org/10.1007/s10657-012-9376-6

Ravankhah M, Schmidt M, Will T (2017) Multi-hazard disaster risk identification for World Cultural Heritage sites in seismic zones. J Cult Herit Manage Sustain Dev. https://doi.org/10.1108/JCHMS D-09-2015-0032

Reimann L, Vafeidis AT, Brown S, Hinkel J, Tol RSJ (2018) Mediterranean UNESCO World Heritage at risk from coastal flooding and erosion due to sea-level rise. Nat Commun. https://doi.org/10.1038/ s41467-018-06645-9 
Ruth M, Coelho D (2007) Understanding and managing the complexity of urban systems under climate change. Clim Policy 7(4):317-336. https://doi.org/10.1080/14693062.2007.9685659

Schmidt-Traub G, Sachs JD (2015) Financing sustainable development: implementing the SDGs through effective investment strategies and partnerships. Sustainable Development Solutions Network.

Schwartz SH (1992) Universals in the content and structure of values: theoretical advances and empirical tests in 20 countries. Adv Exp Soc Psychol. https://doi.org/10.1016/S0065-2601(08)60281-6

Sesana E, Bertolin C, Loli A, Gagnon AS, Hughes J, Leissner J (2019) Increasing the resilience of cultural heritage to climate change through the application of a learning strategy. Communications in Computer and Information Science, pp 402-423. https://doi.org/10.1007/978-3-030-12957-6_29

Sesana E, Gagnon AS, Bonazza A, Hughes JJ (2020) An integrated approach for assessing the vulnerability of World Heritage Sites to climate change impacts. J Cult Herit. https://doi.org/10.1016/j. culher.2019.06.013

Spennemann DHR, Graham K (2007) The importance of heritage preservation in natural disaster situations. Int J Risk Assess Manage. https://doi.org/10.1504/IJRAM.2007.014670

Stern PC, Dietz T, Abel T, Guagnano GA, Kalof L (1999) A value-belief-norm theory of support for social movements: the case of environmentalism. Human Ecol Rev.

Stern PC (2000) New environmental theories: toward a coherent theory of environmentally significant behavior. J Soc Issues. https://doi.org/10.1111/0022-4537.00175

Sugio K (2015) Large-scale disasters on World heritage and cultural heritage in Japan: significant impacts and sustainable management cases. Landsc Res. https://doi.org/10.1080/01426 397.2015.1057806

Surminski S, Bouwer LM, Linnerooth-Bayer J (2016) How insurance can support climate resilience. Nat Clim Change 6(4):333-334. https://doi.org/10.1038/nclimate2979

Surminski S, Eldridge J (2017) Flood insurance in England-an assessment of the current and newly proposed insurance scheme in the context of rising flood risk. J Flood Risk Manage 10(4):415-435. https://doi.org/10.1111/jfr3.12127

Tanner C, Kast SW (2003) Promoting sustainable consumption: determinants of green purchases by Swiss Consumers. Psychology and Marketing. https://doi.org/10.1002/mar.10101

Throsby D (2001) Economics and culture. Cambridge University Press, Cambridge, UK

Throsby D, Zednik A (2014) The economic and cultural value of paintings: some empirical evidence. Handbook of the Economics of Art and Culture. https://doi.org/10.1016/B978-0-444-53776-8.00004-0

Toki K (2011) Protection of cultural heritage from post-earthquake fire. J Disaster Res. https://doi. org/10.20965/jdr.2011.p0004

UNESCO (2006) Climate Change and the World Heritage. Report on predicting and managing the impacts of climate change on World Heritage and Strategy to assist States Parties to implement appropriate management responses. UNESCO World Heritage Centre

UNISDR (2009) UNISDR Terminology on disaster risk reduction. International Strategy for Disaster Reduction (ISDR)

Vecco M, Imperiale F (2017) Cultural heritage: values and measures. What insurance value? J Multidisciplinary Res 9(1):7-22

Wang JJ (2015) Flood risk maps to cultural heritage: measures and process. J Cult Herit. https://doi. org/10.1016/j.culher.2014.03.002

World Bank Group (2017) Promoting disaster resilient cultural heritage. Knowledge Note.

Publisher's Note Springer Nature remains neutral with regard to jurisdictional claims in published maps and institutional affiliations. 